\title{
The genus Rhagomys (Thomas 1917) (Rodentia, Cricetidae, Sigmodontinae) in South America: morphological considerations, geographic distribution and zoogeographic comments
}

\author{
Alexandre Reis Percequillo ${ }^{1, *}$, Flavia P. Tirelli ${ }^{2}$, \\ Fernanda Michalski ${ }^{3,4}$ and Eduardo Eizirik ${ }^{2,3}$ \\ ${ }^{1}$ Departamento de Ciências Biológicas, Escola Superior de \\ Agricultura "Luiz de Queiroz", Universidade de São \\ Paulo, Av. Pádua Dias, 11, Caixa Postal 9, Piracicaba, SP, \\ 13418-900, Brazil, e-mail: percequi@esalq.usp.br \\ ${ }^{2}$ Laboratório de Biologia Genômica e Molecular, \\ Faculdade de Biociências, PUCRS, Av. Ipiranga 6681, \\ prédio 12. Porto Alegre, RS 90619-900, Brazil \\ ${ }^{3}$ Instituto Pró-Carnívoros, Av. Horácio Neto 1030, Atibaia, \\ SP 12945-010, Brazil \\ ${ }^{4}$ Programa de Pós-Graduação em Biodiversidade Tropical, \\ Universidade Federal do Amapá, Rod. Juscelino \\ Kubitschek, Km 02, Macapá, AP, 68902-280, Brazil \\ * Corresponding author
}

Keywords: diversity; molar occlusal pattern; neotropical region; Thomasomyini.

After nearly a century of marginal appearance in the Sigmodontinae literature (Musser and Carleton 2005), the genus Rhagomys (Thomas 1917) has been the focus of considerable attention over the past decade. Owing to new inventories and sampling techniques, several specimens have been obtained that provide important information on the diversity of the genus (Luna and Patterson 2003), geographical distribution and species-specific ranges (Pinheiro et al. 2004, Pardini and Umetsu 2006, Villalpando et al. 2006, Steiner-Souza et al. 2008), as well as on the phylogenetic position of this taxon within the subfamily (Percequillo et al. 2004, D'Elia et al. 2006).

Available evidence suggests that the genus occurs in eastern South America, with most localities restricted to the eastern portion of Santa Catarina, São Paulo, Minas Gerais and Espírito Santo states in Brazil (the range of Rhagomys rufescens - Thomas 1886; see also Steiner-Souza et al. 2008), and at high elevations on the eastern slopes of the Andean Cordillera in Peru and Bolivia (the range of Rhagomys longilingua - Luna and Patterson 2003, see Villalpando et al. 2006). Such a disjunct distribution is observed in other vertebrate and plant groups (Villalpando et al. 2006; Percequillo et al. 2011), but Luna and Patterson (2003) suggested that in the genus Rhagomys this pattern is a sampling artifact. Here, we present new evidence on the dental morphology and geographic distribution of the genus Rhagomys, providing support for Luna and Patterson's (2003) hypothesis.

While identifying small mammal remains found in a single ocelot (Leopardus pardalis) scat sample (Tirelli 2010), we obtained four Rhagomys molars: the first upper left (M1), the first lower right (m1), and the second (m2) and third (m3) lower left molars. As all molars exhibited a similar morphology, moderate wear, and as there is no repetition of teeth, we believe that all belong to the same individual. These molars were deposited at the Museu de Zoologia da Universidade de São Paulo, under the number MZUSP 34889; other specimens were studied to allow correct identification of our molars, housed at institutions listed in Table 1. The collection site was Alta Floresta, northern Mato Grosso state, Brazil, located at $09^{\circ} 53^{\prime} \mathrm{S}, 56^{\circ} 28^{\prime} \mathrm{W}$, a region classified by Köppen (1948) as AMA zone (Tropical monsoon climate), also known as a "Tropical wet climate".

These molars exhibit the following occlusal pattern (Figure 1): upper (M1) and lower (m1, m2 and m3) molars are tubercular and hypsodont; main cusps are conical and isolated, and are oriented posteriorly on upper molars and directed anteriorly in the lower molars; as a consequence, lophs and lophids are rather discrete and flexus and flexids are widely open. Labial and lingual cusps are arranged in alternated pairs, with the lingual cusps slightly anterior to labial ones in M1; in lower molars, the lingual cusps are anterior to labial cusps. Molars exhibit moderate wear and present occlusal surface covered mostly with enamel, with small exhibition of dentine basins restricted to the tip of the main cusps. Labial and lingual styles and stylids are evident in $\mathrm{M} 1, \mathrm{~m} 1, \mathrm{~m} 2$ and $\mathrm{m} 3$. M1 exhibited a deep anteromedian flexus, dividing the anterocone in asymmetrical anterolabial and anterolingual conules (the lingual smaller than the labial). An anteromedian crista is lacking. The anterostyle is well developed, being closely positioned in relation to the paracone. Paracone and metacone connected posteromedially to median mure; the median mure is a distinct medial conule, to which are also connected to mesoloph (labially) and the hypocone (anteromedially). Mesoloph is narrow and low, fused lingualy to mesostyle and medially to median mure. Metacone connected to the posteroloph, which is short and 
Table 1 Individual molars and molar series measurements of genus Rhagomys.

\begin{tabular}{llll}
\hline & Rhagomys sp. & R. longilingua & $R$. rufescens \\
\hline & MZUSP 34889 & MUSM 17013, & MZUSP 31952, MN 66056, MN 65545, BMNH 86.2.8.5, \\
& & FMNH 170687, & AB 401, FURB 9861, FURB 9887, FURB 12010, \\
& & CBF 7620 & FURB 12583 \\
Left M1 length & 2.08 & - & $2.17,-,-,-, 2.19,2.09,2.01,2.08,1.99$ \\
Right m1 length & 1.83 & - & $1.79,-,-,-, 1.85,1.89,1.81,1.91,1.85$ \\
Left m2 length & 1.53 & - & $1.48,-,-,-, 1.53,-,-,-,-$ \\
Left m3 length & 1.41 & - & $1.37,-,-,-, 1.47,-,-,-,-$ \\
Length of upper molar series & - & $4.29,4.53,4.23$ & $4.39,4.56,4.59,4.74,4.69,4.56,4.41,4.44,4.46$ \\
Length of lower molar series & ca. 4.77 & - & $4.68,-,-,-, 4.77,4.63,4.57,4.55,4.53$ \\
Breadth of M1 & 1.18 & $1.26,1.3,1.21$ & $1.23,1.27,1.29,1.31,1.38,1.3,1.25,1.15,1.14$ \\
\hline
\end{tabular}

All measurements are in millimeters. Museum acronyms: AB, Collection of Renata Pardini to be deposited at MZUSP; BMNH, The Natural History Museum; CBF, Colección Boliviana de Fauna; FMNH, The Field Museum; FURB, Fundação Universidade Regional de Blumenau; MUSM, Museo de Historia Natural, Universidad Nacional Mayor de San Marcos; MN, Museu Nacional da Universidade Federal do Rio de Janeiro.

discrete. Lower $\mathrm{m} 1$ with anteroconid much reduced and narrow, not divided by anteromedian flexid; labial cingulum connected to anteroconid extending posteriorly; anterolophid is absent. Metaconid apparently is not connected to anterior murid or to median murid. Protoconid is connected poste-

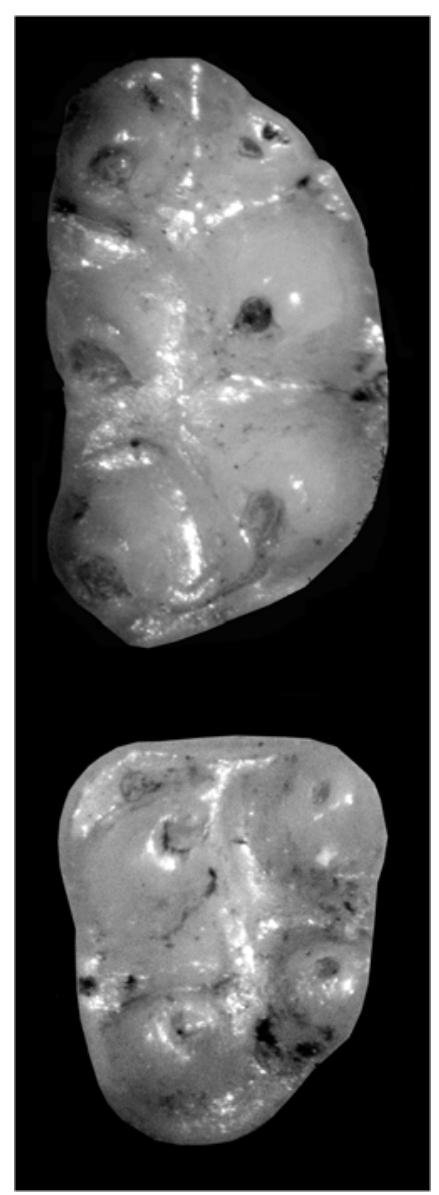

Figure 1 Occlusal molar patterns of genus Rhagomys, left M1 (upper molar) and left $\mathrm{m} 3$ (lower molar), of specimen MZUSP 34889, from Alta Floresta, Mato Grosso, Brazil. romedially to median murid. Mesostylid is well developed, but the mesolophid is lacking. Entoconid is linked to median murid, and marginally connected to posterolophid. Hypoconid is connected to median murid and to posterolophid. Lower $\mathrm{m} 2$ with four cusps equally developed; very similar to $\mathrm{m} 1$. Cingulum anterolabial is well developed, defining a deep protoflexid. Anterolophid is absent. A reduced and narrow mesostylid is present, but not fused to median murid as the mesolophid is absent; mesoflexid absent and entoflexid wide. Entoconid linked to median murid, anteromedially. Posterocrista is present, delimiting a well defined and moderately deep flexid posterior to hypoconid. Posterolophid is long and linked to hypoconid through the posterocrista, extending throughout the posterior margin of the molar forming a posterocingulum (Luna and Patterson 2003). Ectostylid is well developed. Lower $\mathrm{m} 3$ with four cusps most evident, with the entoconid greatly developed; this molar is very similar to $\mathrm{m} 2$. Posterocrista is present, but not evident as in $\mathrm{m} 2$.

The four molars exhibit a similar occlusal pattern (Figure 1) and general length (Table 1) as those previously described by Luna and Patterson (2003) and Percequillo et al. (2004), and can reliably be assigned to the genus Rhagomys (Figure 1). Nevertheless, as we are not aware of any molar-based diagnosis for this genus, we assessed the morphological variation from available data (Luna and Patterson 2003; Percequillo et al. 2004; $R$. rufescens: MZUSP 31952, MN 66056, MN 65545, BMNH 86.2.8.5, AB 356, AB 401; Rhagomys sp.: MZUSP 34889) and present here the traits that we employed to identify these molars as belonging to the genus Rhagomys. The upper and lower molars are tubercular and moderately hypsodont, with conical and isolated cusps directed posteriorly in upper molar and anteriorly in lower molars. In young specimens, the occlusal surface is entirely covered by enamel, whereas in older specimens there is only moderate exposition of dentine, restricted to the tip of main cusps and, more rarely, to some lophs; this small exposition of dentine clearly distinguishes Rhagomys from all other sigmodontine genera, in which there is moderate to large basins of exposed dentine. The M1 presents a deep anteromedian flexus, dividing the anterocone in asymmetrical anterolabial 
and anterolingual conules (the labial is larger). In Rhagomys, the mesoloph (observed in M1 and M2, but reduced on M3) is a narrow and low structure connected to the median mure, which is observable as a distinct conule, a feature exclusive of this genus. These features are observed both in $R$. longilingua and $R$. rufescens, and we believe that they are useful diagnostic traits for the genus.

Nevertheless, there are some other features that could be useful in genus or species recognition, as more specimens become available in the future and we can properly evaluate their individual, geographic and taxonomic variation: relative position of labial and lingual cusps; presence of entoconid; presence of anteromedian crista; presence of posterocrista. In $R$. longilingua, labial and lingual cusps are arranged in slightly alternate pairs, both in maxillar and dentary, whereas in $R$. rufescens these cusps are parallel; the specimen from Mato Grosso presents alternate cusps.

The specimen MZUSP 34889, from Mato Grosso, shares with the paratype of Rhagomys longilingua (FMNH 170867) the presence of a well developed entoconid on $\mathrm{m} 3$, a feature that is reduced or absent in Rhagomys rufescens (see also Luna and Patterson 2003: 11, and Percequillo et al. 2004: 245). It is possible that the presence/absence of entoconid could be of diagnostic value in discriminating $R$. longilingua from $R$. rufescens, but as our knowledge of the variation of molar structures in the genus remains limited, more specimens are required to confirm this hypothesis. In fact, the Bolivian specimen of $R$. longilingua from Bajo Hornuni (CBF 7620) does not exhibit a developed entoconid (J. Vargas, personal communication).

The anteromedian crista is variably present in the type series of $R$. longilingua, and its presence can be related to tooth wear (Luna and Patterson 2003). In all examined specimens of $R$. rufescens, we were not able to observe this structure, even in specimens with moderate to great wear. Consequently, this could be a useful trait to discriminate the former from the latter species. The specimen from Mato Grosso does not exhibit this feature, but the molars are still weakly worn, precluding a more definitive decision.

The posterocrista is apparently a continuation of the median murid (Luna and Patterson 2003; this structure could also be named posterior murid) and it is exhibited by both the holotype and paratype of $R$. longilingua. It is also present in the $\mathrm{m} 2$ and $\mathrm{m} 3$ of the Mato Grosso specimen, but not in $\mathrm{m} 1$. This structure is also not present in any examined specimen of $R$. rufescens.

Quantitatively, both known species also exhibit similar molars in length and width (Table 1). In general, $R$. rufescens presents molars that are slightly longer than those of $R$. longilingua (although some overlap is observed), but their width is similar, a characteristic already observed by Luna and Patterson (2003). The length of combined lower molars of the specimen from Mato Grosso is approximately $4.77 \mathrm{~mm}$ (we summed all available lower molars, both from left and right dentary, just to obtain an idea of the order of magnitude of this series), a value that is included in the variation observed in $R$. rufescens (there is no available information regarding lower molar series length on $R$. longilingua).
Regarding the relative position of cusps, the presence of both the entoconid and the posterocrista, the specimen from Mato Grosso is more similar to $R$. longilingua than to $R$. rufescens. By contrast, the specimen from Mato Grosso does not exhibit the mesolophid in $\mathrm{m} 1, \mathrm{~m} 2$ and $\mathrm{m} 3$, a feature present in both known species. Considering the variation documented above and the fact that both species exhibit very similar molar occlusal patterns, we lack confidence in identifying the molars at the species level: despite the similarity with $R$. longilingua, they could also belong to $R$. rufescens, or to an undescribed form. Considering the remarkable number of new species of sigmodontines described in the past decade (see Percequillo et al. 2011), it would not be surprising if this individual represents a new taxonomic entity.

Our results suggest that out of 82 carnivore scat samples analyzed from a study region that spans $4100 \mathrm{~km}^{2}$, only one Rhagomys individual was consumed. Other small mammal taxa obtained from these scat samples included genera Euryoryzomys, Oligoryzomys, Oxymycterus, Necromys, Akodon, Proechimys, Metachirus and small unidentified didelphids. This region of south-central Amazonia in Mato Grosso state was intensively sampled with conventional and pitfall traps by A.P. Carmignotto from 1995 to 1997 (vouchers deposited at MZUSP; see Percequillo et al. 2005) and other researchers (L.P. Costa and Y. Leite; vouchers at Universidade Federal de Minas Gerais, Belo Horizonte, Brazil and Museum of Vertebrate Zoology, Berkeley, CA, USA), but these inventories failed to produce any specimen of genus Rhagomys. This evidence suggests that the genus occurs only at low abundance and low densities throughout its range.

The fauna described above includes rodent species that are typical of forested habitats (such as genera Euryoryzomys, Metachirus and Proechimys) and from open and transitional areas such as the Cerrado (e.g., Oligoryzomys and Necromys). Alta Floresta is typically covered by Amazon forest, but there are transitional areas relatively close geographically. Moreover, the Alta Floresta region is experiencing a fast deforestation rate, with the replacement of original forest cover by agricultural and pastoral fields, which could account for the presence of typical open vegetation dwellers (Michalski et al. 2008). The same sample that produced the molars of Rhagomys also contained molars of the Akodontini genus Oxymycterus. The only species of this genus known to occur in the area is Oxymycterus amazonicus (Hershkovitz 1994, Hoffman et al. 2002), apparently a forest specialist.

We also furnish an updated map with the collection localities of the genus in South America (Figure 2), with some amendments to previous studies (e.g. Steiner-Souza et al. 2008). The record of $R$. rufescens at "Ibiúna, Caucaia do Alto"' presented by Steiner-Souza et al. (2008) is erroneous, because Ibiúna and Caucaia do Alto are distinct collecting localities that belong to two different municipalities, and it results from information obtained from Pardini and Umetsu (2006) and Umetsu et al. (2006). We studied the voucher specimens collected by R. Pardini and collaborators (AB356 and $\mathrm{AB} 401$ ), and we confidently assigned them to R. rufescens. They were collected at Ribeirão Grande, and not at Parque Estadual Intervales (specimens were obtained outside 


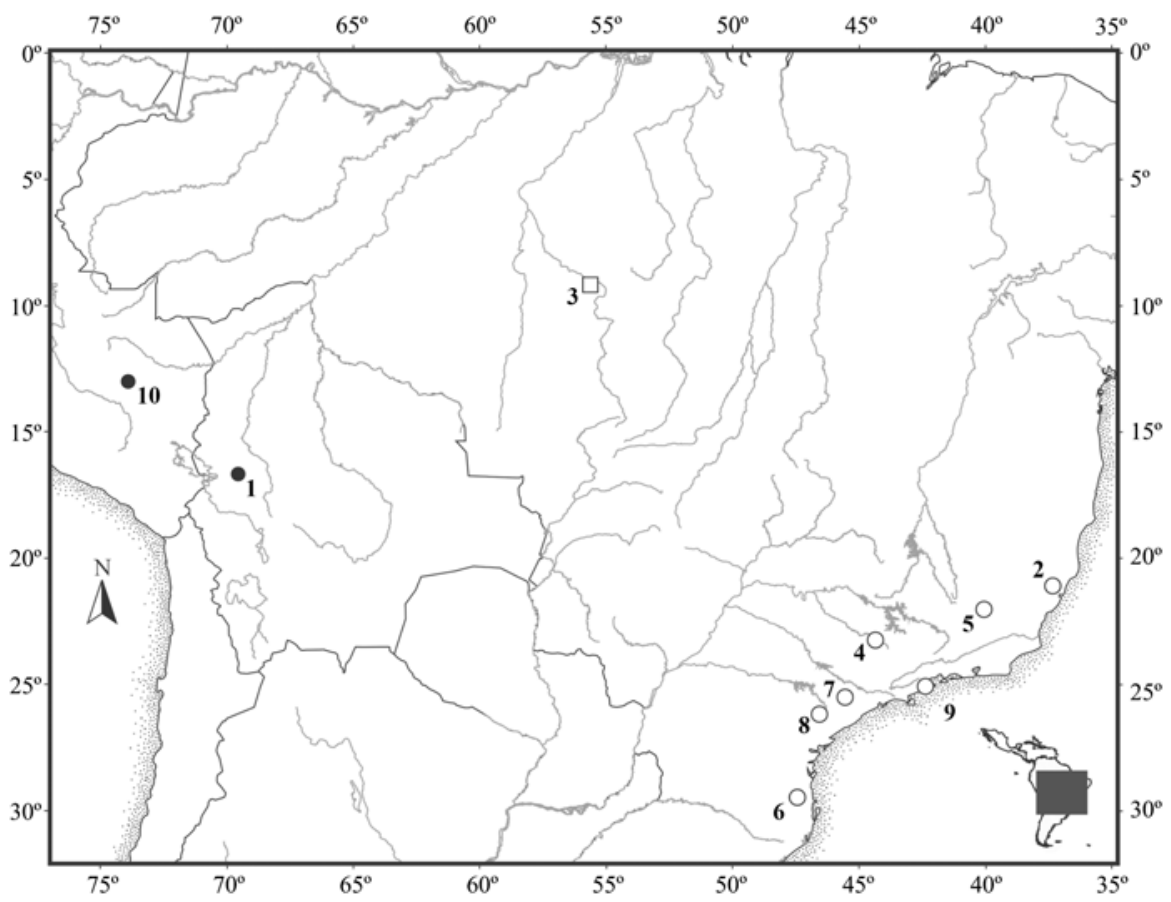

Figure 2 Known collection localities of genus Rhagomys in South America; open circles represent $R$. rufescens, solid dots represent $R$. longilingua and the open square represents the new record presented here. Collection localities: BOLIVIA: La Paz: 1. Bajo Hornuni, Parque Nacional y Area Natural de Manejo Integrado Cotapata ( $\left.16^{\circ} 12.8^{\prime} \mathrm{S}, 67^{\circ} 53.2^{\prime} \mathrm{W}\right)$. BRAZIL: Espírito Santo: 2. Santa Teresa (19 $\left.56^{\prime} \mathrm{S}, 40^{\circ} 36^{\prime} \mathrm{W}\right)$. Mato Grosso: 3. Alta Floresta $\left(09^{\circ} 53^{\prime} \mathrm{S}, 56^{\circ} 28^{\prime} \mathrm{W}\right)$. Minas Gerais: 4. Poços de Caldas $\left(21^{\circ} 47^{\prime} \mathrm{S}, 46^{\circ} 34^{\prime} \mathrm{W}\right)$; 5. Viçosa (20 $\left.45^{\prime} \mathrm{S}, 4^{\circ} 53^{\prime} \mathrm{W}\right)$. Santa Catarina: 6. Mono, Parque Natural Municipal Nascentes do Garcia, Indaial ( $\left.27^{\circ} 01^{\prime} \mathrm{S}, 49^{\circ} 14^{\prime} \mathrm{W}\right)$. São Paulo: 7. Reserva Florestal Morro Grande, Caucaia do Alto $\left(23^{\circ} 41^{\prime} \mathrm{S}, 46^{\circ} 58^{\prime} \mathrm{W}\right)$; 8. Ribeirão Grande $\left(24^{\circ} 10^{\prime} \mathrm{S}, 48^{\circ} 21^{\prime} \mathrm{W}\right)$; 9. Parque Estadual da Serra do Mar, Ubatuba ( $23^{\circ} 26^{\prime} \mathrm{S}$, $\left.45^{\circ} 04^{\prime} \mathrm{W}\right)$. PERU: 10. Cuzco: Suecia, along Río Cosñipata, Manu Biosphere Reserve $\left(13^{\circ} 06.032^{\prime} \mathrm{S}, 71^{\circ} 34.125^{\prime} \mathrm{W}\right)$.

the limits of the Parque Estadual Intervales), and we, therefore, corrected this on the list of collecting localities (Figure 2 , locality 8 ). Thus, to the best of our knowledge, there are no current records of $R$. rufescens from Ibiúna. We also corrected the record from "Reserva Floresta Morro Grande, Ibiúna', (Steiner-Souza et al. 2008), because the correct designation is Reserva Florestal Morro Grande, Caucaia do Alto (locality 7, Figure 2).

Although the specific identification of the Alta Floresta specimen is unclear, the present record is of zoogeographic relevance, because it extends the genus distribution to the southern-central portion of the Amazon Basin, on the Central Brazilian Shield (Figure 2). This locality is approximately $1665 \mathrm{~km}$ northwest from the southeastern-most record of $R$. rufescens (Poços de Caldas, Minas Gerais, Brazil) and nearly $1460 \mathrm{~km}$ east from the western-most collecting locality of $R$. longilingua (Bajo Horoni, La Paz, Bolivia). This new location supports the hypothesis that the genus is widespread in South America, with different species associated with each biome (Luna and Patterson 2003).

A similar pattern of distribution was already described for other Sigmodontinae genera, such as Euryoryzomys [Western Amazon: E. nitidus (Thomas 1884); Central Amazon: E. emmonsae (Musser et al. 1998); Eastern Atlantic Forest: E. russatus (Wagner 1848)] and Hylaeamys [Western Amazon: H. perenensis (Allen 1901); Central Amazon: H. megace- phalus (Fischer 1814); Eastern Atlantic Forest: H. laticeps (Lund 1840)], and other taxa (see Costa 2003). Additionally, the presence of Rhagomys in south-central Amazonia supports the hypothesis of a historical west-east connection between the Amazon and Atlantic forests (Costa 2003, Vivo and Carmignotto 2004). The present finding also highlights the inadequacy of specimens available in museums and scientific collections to develop and test hypotheses on even the most basic aspects of the sigmodontine rodents, such as diversity and geographic distribution. The task ahead to obtain adequate samples so as to be able to propose more sophisticated hypotheses on the evolution and biogeography of such a diverse group of rodents is large, indeed, and ever more pressing given the rate of deforestation over much of the region.

\section{Acknowledgements}

We are deeply indebted to Ulyses Pardiñas, Jim Patton, François Catzeflis, Christiane Denys, and two anonymous reviewers for a critical review of the manuscript; to Julieta Vargas who examined the Bolivian specimen of genus Rhagomys from Colección Boliviana de Fauna; to Sergio Althoff who kindly provided measurements of the molars of specimens housed at FURB; to Paula Jenkins (BMNH) for granting access to the type series of $R$. rufescens; to Mario de Vivo and João A. Oliveira, who allowed us to examine 
specimens at MZUSP and MN, respectively; and to Luiz Simone who kindly allowed us to photograph Rhagomys molars in the Mollusk Laboratory at MZUSP. A.R.P. was sponsored by the American Museum of Natural History, The Field Museum, Smithsonian Institution, and Museum of Comparative Zoology grants as well as Conselho Nacional de Desenvolvimento Científico e Tecnológico $(\mathrm{CNPq})$ and Fundação de Amparo à Pesquisa do Estado de São Paulo (FAPESP, FAPESP Biota Program, FAPESP Programa Jovem Pesquisador) fellowships. Research funding for F.T. was provided by CAPES (Coordenação de Aperfeiçoamento de Pessoal de Nível Superior). F.M. was funded by a FAPESP postdoctoral scholarship (FAPESP 2007/01252-2). E.E. was supported by CNPq (Edital MCT/CNPq 006/2007 and Edital MCT/CNPq 15/2007). Field activities in Alta Floresta were funded by the Wildlife Conservation Society, Conservation, Food and Health Foundation, Cleveland Metroparks Zoo and the Cleveland Zoological Society, The Rufford Small Grants Foundation, and Conservação Internacional do Brasil.

\section{References}

Costa, L.P. 2003. The historical bridge between the Amazon and Atlantic Forest of Brazil: a study of molecular phylogeography with small mammals. J. Biogeogr. 30: 71-86.

D’Elia, G., L. Luna, E.M. Gonzalez and B.D. Patterson. 2006. On the Sigmodontinae radiation (Rodentia, Cricetidae): an appraisal of the phylogenetic position of Rhagomys. Mol. Phylogenet. Evol. 38: 558-564.

Hershkovitz, P. 1994. The description of a new species of South American hocicudo, or long nose mouse, genus Oxymycterus (Sigmodontinae, Muroidea), with a critical review of the generic content. Field. Zool. 79: 1-43.

Hoffman, F., E.P. Lessa and M.F. Smith. 2002. Systematics of Oxymycterus with description of a new species of Uruguay. J. Mammal. 83: 408-420.

Köppen, W. 1948. Climatología: con un estudio de los climas de la tierra. Fondo de Cultura Económica, México. pp. 479.

Luna, L. and B.D. Patterson. 2003. A remarkable new mouse (Muridae: Sigmodontinae) from southeastern Peru: with comments on the affinities of Rhagomys rufescens (Thomas, 1886). Field. Zool. 101: 1-24.
Michalski, F., C.A. Peres and I.R. Lake. 2008. Deforestation dynamics in a fragmented region of southern Amazonia: evaluation and future scenarios. Environ. Conserv. 35: 93-103.

Musser, G.G. and M.D. Carleton. 2005. Superfamily Muroidea. In: (D.E. Wilson and D.A. Reeder, eds.) Mammal species of the world: a taxonomic and geographic reference, 3rd ed. Johns Hopkins University Press, Baltimore, MD. pp. 894-1531.

Pardini, R. and F. Umetsu. 2006. Pequenos mamíferos da Reserva Florestal do Morro Grande distribuição das espécies e da diversidade em uma área de Mata Atlântica. Biota Neotrop. 6: 1-22.

Percequillo, A., P.R. Gonçalves and J.A. Oliveira. 2004. The rediscovery of Rhagomys rufescens (Thomas, 1886), with a morphological re-description and comments on its systematic relationships based on morphological and molecular (cytochrome b) characters. Mamm. Biol. 69: 238-257.

Percequillo, A.R., A.P. Carmignotto and M.J.J. Silva. 2005. A new species of Neusticomys (Ichthyomyini, Sigmodontinae) from central Brazilian Amazonia. J. Mammal. 86: 873-880.

Percequillo, A.R., M. Weksler and L.P. Costa. 2011. A new genus and species of rodent from the Brazilian Atlantic Forest (Rodentia, Cricetidae, Sigmodontinae, Oryzomyini), with comments on Oryzomyine biogeography. Zool. J. Linn. Soc. 161: 357-390.

Pinheiro, P., P. Hartmann and L. Geise. 2004. New record of Rhagomys rufescens (Thomas 1886) (Rodentia: Muridae). Zootaxa 431: $1-11$.

Steiner-Souza, F., P. Cordeiro-Estrela, A.R. Percequillo, A.F. Testoni and S.L. Althoff. 2008. New records of Rhagomys rufescens (Rodentia: Sigmodontinae) in the Atlantic Forest of Brazil. Zootaxa 1824: 28-34.

Tirelli, F.P. 2010. Análise comparativa de nichos tróficos de carnívoros (Mammalia, Carnivora) da região de Alta Floresta, Estado do Mato Grosso, Brasil. MSc dissertation. Universidade Federal do Rio Grande do Sul, Porto Alegre, RS, Brasil. pp. 74.

Umetsu, F., L. Naxara and R. Pardini. 2006. Evaluating the efficiency of pitfall traps for sampling small mammals in the neotropics. J. Mammal. 87: 757-765.

Villalpando, G., J. Vargas and J. Salazar-Bravo. 2006. First record of Rhagomys (Mammalia: Sigmodontinae) in Bolivia. Mastozool. Neotrop. 13: 143-149.

Vivo, M. and A.P. Carmignotto. 2004. Holocene vegetation change and the mammal faunas of South America and Africa. J. Biogeogr. 31: 943-957. 